\title{
PENGAWASAN PARTISIPATIF MASYARAKAT DALAM PEMILIHAN UMUM SERENTAK PRESIDEN/WAKIL PRESIDEN DAN PEMILIHAN UMUM LEGISLATIF TAHUN 2019 DI KABUPATEN KAPUAS
}

\section{Participatory supervision of communities in concurrent elections of the President/Vice president and Legislative elections of the year 2019 in Kapuas Regency}

\section{Tity Yukrisna' \\ M Riban Satia ${ }^{2}$ \\ R Biroum Bernadrianto 3}

Universitas Muhammadiyah Palangkaraya, Palangka Raya, Central Kalimantan, Indonesia

email:

\section{titykalteng@gmail.com}

\section{Kata Kunci:}

Pengawasan

Partisipatif

Pemilihan Umum

\section{Keywords: Supervision Participatory Election}

\section{Accepted}

Januari 2020

\begin{abstract}
Abstrak
Tujuan penelitian ini untuk melihat Pengawasan pemilihan umum yang dilakukan dalam rangka mewujudkan terselenggara Pemilu secara demokratis, langsung, umum, bekas, rahasia, jujur, adil dan berkualitas. Kesuksesan pelaksanaan pemilu merupakan kebutuhan bersama seluruh rakyat. Karena hanya dengan demikian terpilih figur-figur berkualitas yang memimpin bangsa. Pengawasan pelaksanaan pemilu menjadi tanggung jawab bersama. Masyarakat dapat melakukan pengawasan dengan pengawasan partisipatif.
\end{abstract}

Metode penelitian bersifat diskriptif kualitatif, data dikumpul dengan mempergunakan metode teknik wawancara, observasi dan dokumen. Pengolahan data dilakukan dengan kualitif, yakni dengan mempergunakan model analisis data interaktif.

Hasil penelitian menunjukan : (I) Praktek pengawasan partisipasitif dilaksanakan dengan membentuk "Kampung Pengawasan Partisipatif" yang dilaksanakan di Kecamatan Basarang yakni Desa Basarang Jaya, Kecamatan Selat yakni Kelurahan Selat Dalam dan Kecamatan Kapuas Hulu di Desa Dirung Koram; (2) Pola pengawasan yang dikembangkan yakni pembinaan, sosialisasi, diskusi dan musyarawarah dengan para tokoh-tokoh masyarakat tingkat RT, RW, arisan para Ketua RT setiap malam Sabtu, senam kebugaran oleh para ibu-ibu. dan lain-lain; (3) Kampung pengawasan partisipatif masyarakat telah memberikan kontribusi cukup signifikan terhadap hasil pelaksanaan pemilu di wilayah tersebut, hampir semua desa/kelurahan yang menjadi Kampung Pengawasan Partisipatif berhasil melaksanakan kegiatan pemilu dengan aman, tertib, lancar tanpa ada kecurangan yang diukur dengan $0 \%$ laporan pelanggaran;

Saran penelitian adalah (I) Perlu peningkatan kegiatan pelatihan pengawas pemilu partisipatif pada kelompok-kelompok masyarakat di tingkat desa/kelurahan disemua wilayah kecamatan; (2) Memberikan lebih banyak sosialisasi kepada lapisan masyarakat; (3) Mengembangkan keberadaan Kampung Pengawasan Partisipatif yang telah ada agar menjadi budaya politik (political culture), dan membentuk Kampung Pengawasan Partisipatif disemua desa dan kecamatan di Kabupaten Kapuas dan Kalimantan Tengah.

\section{Abstract}

The purpose of this research is to see the supervision of elections conducted to realize the election held democratically, direct, common, used, confidential, honest, fair and quality. The success of electoral implementation is a common necessity for all people. Because only thus elected quality figures to lead the nation. The supervision of election implementation is a shared responsibility. People can conduct supervision with participatory supervision.

The method of research is qualitative, data collected using methods of interview techniques, observations, and documents. Data processing is done with qualitative, which is using an interactive data analysis model.

The results of the study showed: (I) The practice of participatory supervision was carried out by forming a "participatory supervision village" which was held in Basarang subdistrict namely Basarang Jaya Village, Straits district of Inner Straits and Kecamatan Kapuas Hulu in Desa Dirung Koram; (2) Supervision pattern developed namely coaching, socialization, discussion, and deliberation with the community leaders level RT, RW, the Arisan of the chairman of the RT every Saturday night, fitness gymnastics by mothers. and others; (3) Community participatory supervision village has contributed quite significantly to the results of the election implementation in the region, almost all villages/villages that become participatory supervision village successfully carried out the electoral activities safely, orderly, smoothly without any fraud measured by $0 \%$ report violations;

Research advice is (I) need to increase participatory election supervisory training activities in community groups at village/Kelurahan in all areas of the subdistrict; (2) Provide more socialization to the community layer; (3) Develop the presence of participatory supervision village that has been to become political culture, and form a participatory supervision village in all villages and sub-districts in Kapuas and central Kalimantan. 


\section{PENDAHULUAN}

Dalam sistem negara demokrasi, pemilihan umum yang selanjutnya disingkat 'Pemilu' merupakan salah satu indikator dan tolak ukur penting pelaksanaan. Hampir semua negara di dunia melaksanakan kegiatan 'Pemilu' sebagai wahana untuk memberikan kesempatan pada masyarakat dan elite kekuasaan melakukan sirkulasi dan rekruitmen untuk berbagai jabatan-jabatan kekuasaan politik dan pemerintahan baik di lembaga legislatif (DPR RI, DPD RI, DPRD Provinsi dan DPRD Kabupaten/Kota), lembaga eksekutif (Presiden/Wakil Presiden, Gubernur/Wakil Gubernur, Walikota/Wakil Walikota dan Bupati/Wakil Bupati) secara periodik 5 (lima) tahun sekali.

Kegiatan pengawasan pemilu menjadi bagian penting dalam proses pelaksanaan pemilu. Pengawasan pemilu dilakukan baik oleh lembaga penyelenggara pemilu yakni Badan Pengawas Pemilu (Bawaslu) dari semua tingkatannya, juga dilakukan masyarakat dan lembaga pemerhati atau pemantau pemilu. UndangUndang Nomor 7 Tahun 2017 tentang Pemilihan Umum Pasal 89 ayat (I) menyatakan : pengawasan penyelenggaraan pemilu dilakukan oleh Bawaslu yang terdiri atas Bawaslu, Bawaslu Provinsi dan Bawaslu Kabupaten/Kota, Panwaslu Kecamatan, Panwaslu Desa/Kelurahan, Panwaslu LN dan Pengawas TPS.

Pengawasan pelaksanaan pemilu di Indonesia secara melembagaan ditetapkan sejak berlakunya Undang-Undang Nomor 12 Tahun 2003 tentang Pemilihan Umum Anggota Dewan Perwakilan Rakyat, Dewan Perwakilan Daerah dan Dewan Perwakilan Rakyat Daerah. Lembaga pengawasan ini kemudian dikuatkan kembali dengan dibentuknya lembaga pengawasan pemilu yang bersifat tetap berdasarkan Undang-Undang Nomor 22 Tahun 2007 tentang Penyelenggara Pemilu dengan dibentuknya sebuah lembaga tetap yang dinamakan Badan Pengawas Pemilu (Bawaslu). Dinamika kelembagaan pengawas Pemilu ternyata masih berjalan dengan terbitnya UndangUndang Nomor 15 tahun 201 I tentang Penyelenggara
Pemilu. Secara kelembagaan pengawas Pemilu dikuatkan kembali dengan dibentuknya lembaga tetap Pengawas Pemilu di tingkat provinsi dengan nama Badan Pengawas Pemilu Provinsi (Bawaslu Provinsi) sebagaimana diatur dalam Undang-Undang Nomor 7 Tahun 2017 tentang Pemilihan Umum menggantikan Undang-Undang Nomor 15 Tahun 20II.

Pelaksanaan pengawasan pemilu yang demokratis, tentu tidak hanya dilaksanakan secara mutlak oleh Badan Pengawas Pemilu (Bawaslu) Pusat dan Badan Pengawas Pemilu Daerah. Pemilu demokratis membutuhkan peran partisipasi masyarakat pada semua proses tahapan penyelenggaraan pemilu, termasuk peran partisipasi masyarakat dalam pengawasan pelaksanaan pemilu itu sendiri.

Keterlibatan masyarakat dalam pengawasan pemilu melalui pemantauan pemilu dan lain-lain menjadi sangat penting sebagai komponen informasi bagi masyarakat umum, peserta dan penyelenggara pemilu terkait proses pelaksanaan pemilu.

Pengawasan pemilu oleh masyarakat menjadi bagian penguatan pelaksanaan pemilu yang demokratis, dimana dengan adanya pemantauan yang dilakukan oleh komponen masyarakat secara terlembaga, akan menjadi bahan penyeimbang kegiatan pelaksanaan pemilu yang dilakukan peserta pemilu dan lembaga penyelenggara pemilu resmi seperti KPU dan Bawaslu. Dengan keterlibatan masyarakat pada kegiatan pengawasan Pemilu secara langsung, maka masyarakat dapat mengikuti dinamika politik yang terjadi dan secara tidak langsung belajar tentang penyelenggaraan Pemilu dan semua proses yang berlangsung. Bagi penyelenggara Pemilu, kehadiran pengawasan masyarakat yang masif akan mengawal dan mengingatkan mereka untuk senantiasa berhati-hati, jujur dan adil dalam penyelenggaraan pemilu (Badan Pengawas Pemilu 2017 :2).

Pelaksanaan pemilu serentak 2019 memiliki arti strategis dalam pelaksanaan pemilu, mengingat pelaksanaan kegiatan yang dilakukan secara serentak 
Tity Yukrisna, M Riban Satia, R Biroum Bernardianto . 2020. Participatory supervision of communities in concurrent elections of the President/Vice president and Legislative elections of the year 2019 in Kapuas Regency

akan dapat sangat mempengaruhi kualitas pelaksanaan dan hasil pemilu secara jujur, adil, bebas, rahasia dan demokratis dengan teori efek ekor jas (coat tail effect).

\section{METODOLOGI}

Penelitian ini menggunakan pendekatan diskriftif kualitatif yang lebih didasarkan atas pertimbangan fenomena kajian yang dipecahkan serta relevansi atas konteks lapangan dalam mengungkap pola pelaksanaan Pengawasan partisipatif masyarakat dalam penyelenggaraan pemilu serentak Presiden/ Wakil Presiden dan pemilu Legislatif pada tahun 2019 di Kaabupaten Kapuas yang sangat dinamis.

Subyek penelitian ini adalah para komisioner Bawaslu Kabupaten Kapuas yang terdiri dari 5 (lima) orang serta unsur Sekretariat Bawaslu Kabupaten Kapuas baik Koordinator Sekretariat maupun Staf. Obyek penelitian diarahkan kepada kelompok masyarakat secara individual dan secara kelembagaan yang berperan serta berkontribusi dalam kegiatan pengawasan masyarakat baik secara ekstra formal dan formal. Jumlah informen ditetapkan berdasarkan kondisi lapangan serta kebutuhan data yang diperlukan.

Adapun penelitian ini dilaksanakan di Kota Kuala Kapuas sebagai tempat kedudukan ibukota Pemerintah Kabupaten Kapuas. Kota Kuala Kapuas dipilih sebagai lokasi penelitian mengingat daerah Kabupaten Kapuas merupakan kabupaten terpadat penduduk ke-dua di Kalimantan Tengah setelah Kabupaten Kotawaringin Timur, sehingga massa pemilih yang ditetapkan dalam daftar pemilih tetap (DPT) relatif cukup besar.

\section{HASIL DAN PEMBAHASAN}

Penyelenggara Pemilu terdiri dari Komisi Pemilihan Umum (KPU), Badan Pengawas Pemilu (Bawaslu) dan Dewan Kehormatan Penyelenggra Pemilu (DKPP). Ketiga lembaga inilah yang menerjemahkan Undang-Undang Pemilu serta melaksanakannya dengan asas-asas berkeadilan dan setara. KPU sebagai pelaksana teknis penyelengaraan pemilihan umum tentu mendapat porsi perhatian yang lebih besar dalam pengawasan.

Akan banyak pihak yang berkepentingan untuk menjadikan KPU dan Bawaslu sebagai koasi kekuasaannya. Dalam tahap inilah diperlukannya pengawalan pada setiap tahapan penyelenggaraan.

Di Kabupaten Kapuas pola Pengawasan Partisipasitif Masyarakat Dalam Pemilu serentak Presiden/Wakil Presiden dan Pemilu Legislatif Tahun 2019 dilaksanakan oleh masyarakat dengan membentuk “Kampung Pengawasan Partisipasif” seperti diungkapkan Herigalis,SP selaku Koordinator Divisi Pengawasan, Hubungan Masyarakat dan Hubungan Antar Lembaga, yang menyatakan :

"Pola pengawasan partisifatif masyarakat di Kabupaten Kapuas dilaksanakan dalam bentuk pembentukan Kampung Pengawasan Partisipatif Masyarakat yang dilaksanakan sendiri oleh masyarakat atas kesadarannya, dengan dibantu pembinaan dari Bawaslu Kabupaten Kapuas dalam bentuk memberikan penyuluhan dan pendampingan serta pemberian bantuan alat peraga seperti bukubuku, leaflet terkait pelaksanaan pengawasan pemilu diwilayah desa tertentu. Desa atau keluarahan yang berhasil dibentuk adalah di Kecamatan Basarang yakni Desa Basarang Jaya, Kecamatan Selat yakni Kelurahan Selat Dalam dan Kecamatan Kapuas Hulu di Desa Dirung Koram" (Wawancara 17 Nopember 2019).

Kampung Pengawasan Partisifatif masyarakat di Kabupaten Kapuas pada Pemilu Presiden/Wakil Presiden dan Pemilu Legislatif 2019 dibentuk oleh masyarakat di 3 (tiga) wilayah desa/kelurahan seperti diuraikan pada tabel dibawah ini yakni :

Tabel 4.6. Kampung Pengawasan Partisipatif Pemilu Presiden/Wakil Presiden dan Pemilu Legislatif Kabupaten Kapuas Tahun 2019

\begin{tabular}{|l|l|l|}
\hline No. & Kampung/Desa & \multicolumn{1}{|c|}{ Kecamatan } \\
\hline 1. & $\begin{array}{l}\text { Desa Basarang } \\
\text { Jaya }\end{array}$ & Kecamatan Basarang \\
\hline 2. & $\begin{array}{l}\text { Kelurahan Selat } \\
\text { Dalam }\end{array}$ & Kecamatan Selat \\
\hline 3. & $\begin{array}{l}\text { Desa Dirung } \\
\text { Koram }\end{array}$ & Kecamatan Kapuas Hulu \\
\hline \multicolumn{2}{|c|}{ Sumber : Hasil data lapangan } \\
\hline
\end{tabular}

Kampung Pengawasan Partisipatif masyarakat dibentuk sebagai sarana kumpul diskusi pengawasan 
partisipatif masyarakat tentang pengawasan pada tahapan Pemilu. Gagasan ini muncul dari inisiatif masyarakat sendiri untuk mendapatkan pemahaman tentang Pemilu dan pastinya dapat meminimalisir terjadinya pelanggaran pada saat berlangsungnya tahapan Pemilu. Kampung Pengawasan Partisipatif juga menjadi bukti telah terbentuknya partisipasi masyarakat untuk bersama-sama menjaga Pemilu yang aman dan damai.

Kegiatan pengawasan masyarakat dilakukan mulai dari tahap perencanaan sampai pada tahapan pelaksanaan dan penghitungan. Masyarakat pada kampung pengawasan partisipatif dilibatkan secara aktif pada berbagai proses-proses pelaksanaan tahapan pemilu, dengan dibantu dan difasilitasi oleh Bawaslu Kabupaten Kapuas dan Panwascam.

PembentukanKampung Pengawasan Partisipatif masyarakat di 3 desa/kelurahan Kabupaten Kapuas dapat diuraikan sebagai berikut :

\section{Kampung Pengawasan Partisipatif \\ Masyarakat Desa Basarang Jaya}

Desa Basarang Jaya Kecamatan Basarang menjadi salah satu Kampung Pengawasan Partisipatif. Luas desa sekitar $5 \mathrm{Km} 2$ dan berjarak kurang lebih $10 \mathrm{Km}$ dari pusat kota Kabupaten Kapuas. Kepala Desa yang menjabat yakni Bapak Wayan Salop. Jumlah penduduk yang bermukim di desa Basarang Jaya ada sekitar 1338 orang dan DPT sekitar I.088 orang. Peresmiannya di hadiri langsung oleh Wakil Bupati Kapuas H M Nafiah Ibnor di Pendopo Pura Jagat Natha Desa Basarang Jaya km 10, pada 26 Februari 2019. Peresmian sendiri dilakukan oleh Anggota Bawaslu RI Rahmat Bagja, SH. LL. M, selaku Koordinator Divisi Penyelesaian Sengketa.

Gambar 4.5. Gambar Pembentukan Kampung Partisipatif Pengawasan Pemilu Desa Basarang Jaya Kecamatan

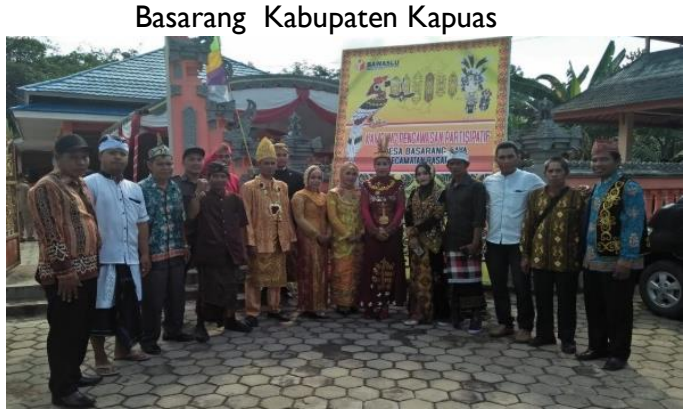

2. Kampung Pengawasan Partisipatif Masyarakat Kelurahan Selat Dalam

Kelurahan Selat Dalam bagian dari Kecamatan Selat juga menjadi Kampung Pengawasan Partisipatif. Luas wilayah kecamatan Selat Dalam kurang lebih $10 \mathrm{Km} 2$. Jumlah DPT yang terdaftar pada Pemilu Tahun 2019 sekitar 8180 orang. Lurah yang menjabat saat ini Bapak Saipul Fajri, S. IP diresmikan tanggal 26 Februari 2019.

Gambar 4.6. Gambar Pembentukan Kampung Partisipatif Pengawasan Pemilu Keluarahan Selat Dalam Kecamatan Selat Kabupaten Kapuas

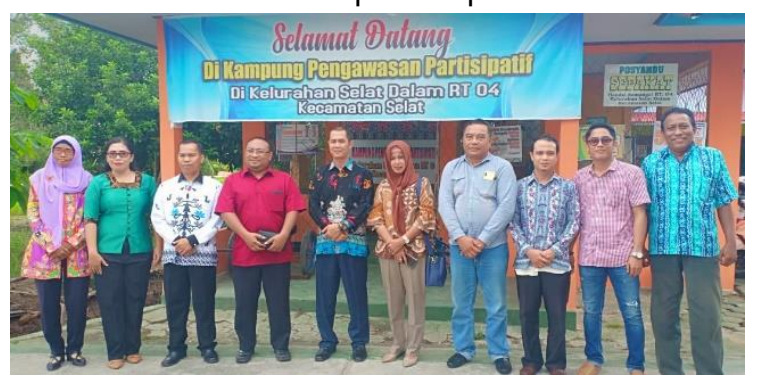

3. Kampung Pengawasan Partisipatif

Masyarakat Desa Dirung Koram

Desa Dirung Koram berada di Kecamatan Kapuas Hulu, yang berjarak tempuh sekitar $234 \mathrm{Km}$ dari pusat Kota Kabupaten Kapuas. Luas wilayah desa tersebut sekitar $40 \mathrm{~km}^{2}$. Jumlah penduduk sekitar 56 I orang dengan DPT berjumlah 215 orang. Kepala desa yang menjabat saat ini Bapak Asih O. Gani. Di resmikan atas inisiatif Ketua Panwaslu Kecamatan Kapuas Hulu tanggal 12 Desember 2018.

Gambar 4.7. Gambar Pembentukan Kampung Partisipatif Pengawasan Pemilu Desa Dirung Koram Kecamatan Kapuas Hulu Kabupaten Kapuas

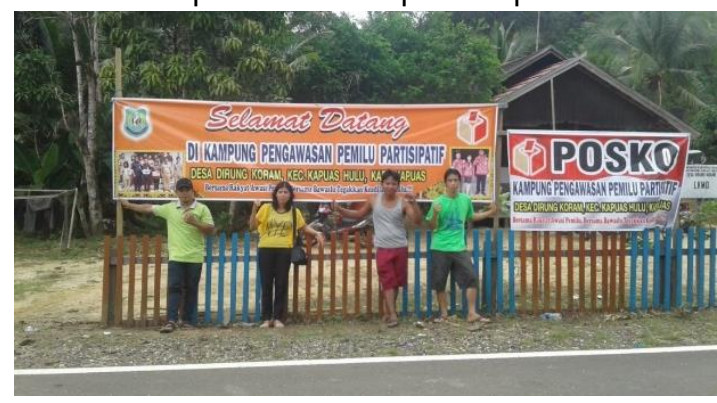

Pola Kampung Pengawasan Partisipatif Pemilu Masyarakat dalam melaksanakan kegiatan pengawasan dan mensukseskan penyelenggaraan pemilu yang jujur, adil dan demokratis dilakukan dalam berbagai bentuk. 
Tity Yukrisna, M Riban Satia, R Biroum Bernardianto . 2020. Participatory supervision of communities in concurrent elections of the President/Vice president and Legislative elections of the year 2019 in Kapuas Regency

Masing-masing Kampung Pengawasan Partisipatif

Pemilu masyarakat menggunakan pola-pola pengawasan partisipatif secara variatif seperti diungkapkankan Komisioner Bawaslu Kapuas Herigalis, SP yakni :

- Pada Desa Basarang Jaya diadakan sosialisasi serta diskusi dengan semua Ketua RT yang diharapkan sosialisasi ini menjadi sarana edukasi agar bisa terhindar dari resiko pelanggaran pemilu. Dengan diadakannya diskusi dengan Ketua RT ini juga, maka dimaksudkan penyampaian ke semua warga masyarakat bisa lebih cepat. Sosialisasi ini juga berguna meningkatkan minat masyarakat dalam menggunakan hak pilihnya dan menolak informasi hoak yang beredar.

- Kampung Pengawasan Partisipatif Kelurahan Selat Dalam melakukan kegiatan dengan mengadakan arisan Ketua RT se-kelurahan Selat Dalam setiap pekan. Kemudian setiap Sabtu pagi juga diadakan senam kebugaran jasmani (SKJ) oleh ibu-ibu PKK dan warga setempat. Metode kegiatan yang dilakukan ini diharapkan dapat menjalin tali silahturahmi dan akan muncul keterbukaan warga masyarakat untuk melaporkan setiap penyimpangan seperti money politic. Adanya sosialisasi tentang pencegahan pelanggaran pemilu memang sangat penting. Apabila suatu saat ditemukan pelanggaran segera melaporkan hal tersebut pada Bawaslu Kabupaten atau jajaran dibawahnya

- Kampung Pengawasan Partisipatif Desa Dirung Koram dilaksanakan dalam bentuk kegiatan sosialisasi dan diskusi dengan tokoh masyarakat setempat.

Kegiatan Kampung Pengawasan Partisipatif Pemilu Masyarakat telah memberikan kontribusi cukup signifikan terhadap hasil pelaksanaan pemilu di wilayah tersebut, hampir semua desa/kelurahan yang menjadi Kampung Pengawasan Partisipatif Pemilu berhasil melaksanakan kegiatan pemilu dengan aman, tertib, lancar tanpa ada kecurangan yang berarti (0\% pelanggaran) yang diukur dari tidak adanya laporan pelanggaran baik oleh partai politik peserta pemilu, masyarakat dan lainnya. Kemudian, Peran partisipasi masyarakat dalam pengawasan pemilu melalu pembentukan Kampung Pengawasan Partisipatif Pemilu cukup memberikan hasil dimana tingkat partisipasi masyarakat rata-rata diatas $80-90 \%$.

Berdasarkan data Bawaslu Kabupaten Kapuas jumlah laporan/pengaduan pelanggaran Pemilu Legislatif dan Pemilu Presiden/Wakil Presiden Tahun 2019 di Kabupaten Kapuas cukup sedikit yaitu sebanyak 6 (enam) laporan yang disampaikan ke Bawaslu Kabupaten Kapuas, namun semua tidak dapat di tindaklanjuti. 4 (empat) dari laporan tersebut telah di register oleh Bawasu Kabupaten Kapuas dan mengandung unsur peanggaran tindak pidana pemilu sehingga harus dibahas bersama Sentra Gakkumdu Kabupaten Kapuas. Namun sampai pembahasan tahap kedua ternyata tidak terpenuhi unsur yang disangkakan sehingga tidak dapat ditindaklanjuti. Sementara 2 (dua) dari laporan tersebut tidak dapat di register dikarenakan tidak terpenuhi syarat formil maupun materiil dan sudah meewati batas waktu (kadaluarsa).

Terkait kesadaran masyarakat melaksanakan fungsi pengawasan secara independen impartiality (berimbang/tidak berpihak) , transparansi, efesiensi serta service- mindedness relatif baik yang rinciannya sebagai berikut :

I. Dalam pelaksanaan prinsip independensi yang dilaksanakan oleh kelompok masyarakat dalam pengawasan pemilihan umum serentak Presiden/Wakil Presiden dan Pemilihan Umum Legislatif tahun 2019 di Kabupaten Kapuas sudah dilaksanakan dengan baik dalam menjalankan segala tugas dan fungsinya tanpa ada pengaruh oleh partai politik tertentu, atau pejabat Negara.

2. Dalam pelaksanan prinsip impartiality (berimbang/tidak berpihak) dinyatakan bahwa penyelenggara pemilu tidak boleh tunduk pada arahan dari pihak manapun, baik pihak berwenang maupun pihak partai politik. Lembaga ini harus 
mampu menjalankan dan bekerja tanpa pemihakan dan praduga politik, serta bebas dari campur tangan, karena akan memiliki dampak langsung tidak hanya terhadap kredibilitas lembaga penyelenggara, tetapi juga terhadap proses dan hasil pemilu. Perlakuan yang sama, tidak memihak, dan adil sehingga tidak memberikan keuntungan pihak lain merupakan makna imparsialitas. Prinsip Imparsial, kelompok masyarakat dalam pengawasan pemilihan umum serentak Presiden/Wakil Presiden dan Pemilihan Umum Legislatif tahun 2019 di Kabupaten Kapuas sudah dilaksanakan dengan baik dimana pemilu kali ini kelompok masyarakat tidak tunduk pada arahan dari pihak manapun, baik pihak berwenang maupun pihak partai politik.

3. Pelaksanaan prinsip transparansi pada proses penyelenggaraan pemilu adalah kewajiban maka dari itu pengawasan partisipatif masyarakat dalam pemilihan umum serentak Presiden/Wakil Presiden dan Pemilihan Umum Legislatif tahun 2019 di Kabupaten Kapuas membuka keterbukaan publik sesuai dengan Undang-Undang Keterbukaan Informasi Publik dengan membentuk PPIP untuk melayani permintaan informasi dari masyarakat terkait penyelenggaraan pemilihan umum serentak Presiden/Wakil Presiden dan Pemilihan Umum Legislatif tahun 2019 di Kabupaten Kapuas. Prinsip Tranparansi, kelompok masyarakat dalam melakukan pengawasan pemilihan umum serentak Presiden/Wakil Presiden dan Pemilihan Umum Legislatif tahun 2019 di Kabupaten Kapuas sudah dilaksanakan dengan baik dimana setiap hasil telah dilakukan keterbukaan akses terhadap publik, dimana dapat diakses secara bebas oleh publik yang ingin mengetahui berbagai informasi tentang proses tahapan pilkada seperti adanya quick account.

4. Prinsip efisiensi dalam pemilihan umum serentak Presiden/Wakil Presiden dan Pemilihan Umum Legislatif tahun 2019 di Kabupaten Kapuas sudah dilaksanakan dengan baik dan berjalan dengan lancar. Serta Prinsip layanan, kelompok masyarakat dalam melaksanakan pengawasan pemilihan umum serentak Presiden/Wakil Presiden dan Pemilihan Umum Legislatif tahun 2019 di Kabupaten Kapuas sudah dilaksanakan dengan baik karena pelayanan yang diberi oleh kelompok masyarakat di Kapuas kepada peserta, dianggap bagus oleh semua peserta pemilu, meskipun belum memberikan kepuasan terhadap semua orang. Kampung Pengawasan Partisipatif juga menjadi bukti telah terbentuknya partisipasi masyarakat untuk bersama-sama menjaga Pemilu yang aman dan damai.

Atas berbagai kegiatan yang dilakukan masyarakat dalam mendukung keberhasilan pelaksanaan pemilu sehingga dapat berjalan dengan berkualitas, jujur, adil, rahasia, partisipatif, Bawaslu Kabupaten Kapuas memberikan apresiasi kepada kawasan, dimana masyarakatnya punya inisiatif untuk berperan aktif melakukan pengawasan jika ada pelanggaran pada proses tahapan Pemilu lalu. Bentuk apresiasi yang dimaksud ialah pemberian piagam penghargaan kepada desa/kelurahan yang telah bekerjasama menjaga Pemilu yang aman dan damai.

Desa/kelurahan yang diberikan penghargaan pertama kalinya adalah Kelurahan Selat Dalam, Kecamatan Selat. Piagam penghargaan diserahkan oleh Ketua Bawaslu Kabupaten Kapuas Iswahyudi Wibowo, SH kepada Ketua RT 04 Selat Dalam Bapak Hamsan didampingi Anggota Bawaslu Kabupaten Kapuas yakni Bapak Herigalis Mahar, SP, Bapak Drs. Libu, Bapak Charles B. Kanta, SP, Ibu Ana Rahimah, SE.I dan Koordinator Sekretariat Bapak Untung Supriadi, SE yang juga turut dihadiri Lurah Selat Dalam Bapak Saiful Fazri, S.IP pada hari Jumat, 19 Juli 2019.

Bawaslu Kabupaten Kapuas juga memberikan piagam penghargaan kepada Desa Basarang Jaya pada hari Senin tanggal 05 Agustus 2019. Piagam diserahkan kepada Kepala Desa yaitu Bapak Wayan Salop. Turut dihadiri Sekertaris Desa Bapak Nyoman Suwinde serta pejabat Kantor Kepala desa dan warga setempat. Acara 
Tity Yukrisna, M Riban Satia, R Biroum Bernardianto . 2020. Participatory supervision of communities in concurrent elections of the President/Vice president and Legislative elections of the year 2019 in Kapuas Regency

dilaksanakan di Kantor Kepala Desa Basarang Jaya tepat pukul 09.30 WIB.

Piagam terakhir diberikan Bawaslu Kabupaten Kapuas kepada kepada Desa Dirung Koram pada hari Rabu tanggal 07 Agustus 2019 yang diserahkan Ketua Bawaslu Kabupaten Kapuas dan diterima langsung Kepala Desa Dirung Koram.

Dengan adanya Kampung Pengawasan Partisipasif ini diharapkan kualitas pelaksanaan pemilu yang melibatkan masyarakat pada kegiatan pengawasan dapat menciptakan sistem demokrasi yang lebih bagi masyarakat Kabupaten Kapuas dan Negara Kesatuan Republik Indonesia.

\section{Faktor - Faktor Mendukung dan Penghambat Pelaksanaan Pengawasan Partisiparif Masyarakat}

Ada beberapa faktor yang dapat mempengaruhi partisipasi masyarakat dalam suatu program, sifat faktor-faktor tersebut dapat mendukung suatu keberhasilan program namun ada juga yang sifatnya dapat menghambat keberhasilan program. Secara umum ada 2 (dua) faktor yang menentukan yakni:

\section{Faktor Internal}

Menurut Angell (dalam Ross, 1967: 130) mengatakan partisipasi yang tumbuh dalam masyarakat dipengaruhi oleh banyak faktor seperti faktor usia, terbatasnya harta benda, pendidikan, pekerjaan dan penghasilan. Faktor-faktor Internal yang mempengaruhi kecenderungan seseorang dalam berpartisipasi, yaitu :

a. Usia

Faktor usia merupakan faktor yang mempengaruhi sikap seseorang terhadap kegiatan-kegiatan kemasyarakatan yang ada. Mereka dari kelompok usia menengah ke atas dengan keterikatan moral kepada nilai dan norma masyarakat yang lebih mantap, cenderung lebih banyak yang berpartisipasi daripada mereka yang dari kelompok usia lainnya.

b. Jenis kelamin

Nilai yang cukup lama dominan dalam kultur berbagai bangsa mengatakan bahwa pada dasarnya tempat perempuan adalah "di dapur" yang berarti bahwa dalam banyak masyarakat peranan perempuan yang terutama adalah mengurus rumah tangga, akan tetapi semakin lama nilai peran perempuan tersebut telah bergeser dengan adanya gerakan emansipasi dan pendidikan perempuan yang semakin baik.

c. Pendidikan

Dikatakan sebagai salah satu syarat mutlak untuk berpartisipasi. Pendidikan dianggap dapat mempengaruhi sikap hidup seseorang terhadap lingkungannya, suatu sikap yang diperlukan bagi peningkatan kesejahteraan seluruh masyarakat.

d. Pekerjaan dan penghasilan

Hal ini tidak dapat dipisahkan satu sama lain karena pekerjaan seseorang akan menentukan berapa penghasilan yang akan diperolehnya. Pekerjaan dan penghasilan yang baik dan mencukupi kebutuhan sehari-hari dapat mendorong seseorang untuk berpartisipasi dalam kegiatan-kegiatan masyarakat. Pengertiannya bahwa untuk berpartisipasi dalam suatu kegiatan, harus didukung oleh suasana yang mapan perekonomian.

e. Lamanya tinggal

Lamanya seseorang tinggal dalam lingkungan tertentu dan pengalamannya berinteraksi dengan lingkungan tersebut akan berpengaruh pada partisipasi seseorang. Semakin lama ia tinggal dalam lingkungan tertentu, maka rasa memiliki terhadap lingkungan cenderung lebih terlihat dalam 
partisipasinya yang besar dalam setiap kegiatan

lingkungan tersebut.

Berdasarkan data lapangan sebagaimana temuan penelitian dapat disimpulkan bahwa Faktor Internal yang mendukung dan menghambat pelaksanaan kelompok masyarakat dalam pengawasan partisipatif masyarakat di pemilihan umum serentak Presiden/Wakil Presiden dan Pemilihan Umum Legislatif tahun 2019 di Kabupaten Kapuas adalah Faktor usia, jenis kelamin, pendidikan, pekerjaan/penghasilan, lamanya tinggal disuatu lingkungan, lemahnya kapasitas kelompok masyarakat dalam pengawas, Pembinaan terhadap kelompok masyarakat dalam melakukan pengawas pemilu melalui kegiatan supervise.

\section{Faktor Eksternal}

Faktor yang mempengaruhi partisipasi masyarakat dalam suatu program juga dapat berasal dari unsur luar/lingkungan. Menurut Holil (1980: 10) ada 4 poin yang dapat mempengaruhi partisipasi masyarakat yang berasal dari luar/lingkungan, yaitu:

a. Komunikasi yang intensif antara sesama warga masyarakat, antara warga masyarakat dengan pimpinannya serta antara sistem sosial di dalam masyarakat dengan sistem di luarnya;

b. Iklim sosial, ekonomi, politik dan budaya, baik dalam kehidupan keluarga, pergaulan, permainan, sekolah maupun masyarakat dan bangsa yang menguntungkan bagi serta mendorong tumbuh dan berkembangnya partisipasi masyarakat;

c. Kesempatan untuk berpartisipasi. Keadaan lingkungan serta proses dan struktur sosial, sistem nilai dan norma-norma yang memungkinkan dan mendorong terjadinya partisipasi sosial;

d. Kebebasan untuk berprakarsa dan berkreasi. Lingkungan di dalam keluarga masyarakat atau lingkungan politik, sosial, budaya yang memungkinkan dan mendorong timbul dan berkembangnya prakarsa, gagasan, perseorangan atau kelompok.

Dapat disimpulkan bahwa Faktor Eksternal yang mendukung dan menghambat kelompok masyarakat dalam pelaksanaan pengawasan partisipatif masyarakat dalam pemilihan umum serentak Presiden/Wakil Presiden dan Pemilihan Umum Legislatif tahun 2019 di Kabupaten Kapuas adalah Komunikasi, Iklim sosial, ekonomi, politik, budaya, Kesempatan untuk berpartisipasi dalam pelaksanaan pengawasan partisipatif masyarakat serta Kebebasan untuk berprakarsa dan berkreasi.

Pengawasan pemilihan umum dilakukan dalam rangka mewujudkan terselenggara Pemilu secara demokratis, langsung, umum, bekas, rahasia, jujur, adil dan berkualitas serta dilaksanakan peraturan perundang-undangan mengenai pemilihan umum secara menyeluruh. Adanya pengawasan juga untuk menegakan integritas penyelenggara, tranparansi penyelenggara dan akuntabilitas hasil pemilihan umum.

Disinilah pentingnya Bawaslu sebagai penjamin nilai-nilai demokrasi, sehingga demokrasi prosedur yang dijalankan selaras dengan demokrasi substantive yang menjadi cita- cita bersama seluruh rakyat dan bangsa Indonesia. Bawaslu memiliki makna penting bagi penjamin terlaksananya demokrasi di ruang publik. Demokrasi mensyaratkan adanya peran serta rakyat (anggota ruang publik) dalam menentukan tata kehidupan bersama dan menjadikan negara layak huni, manusiawi dan baik.

Mengapa pengawasan diperlukan, alasan mendasarnya terutama karena Politik memiliki dimensi pelanggaran (violatif). Artinya politik rentan terhadap kekerasan, manipulasi, intrik-intrik, strategi kotor, ketidakadilan sistematis, kerancuan dan kekacauan. Kecenderungan ini mungkin saja terjadi dan kerap terjadi, karena itu diperlukan mekanisme pengawasan yang memastikan proses 
Tity Yukrisna, M Riban Satia, R Biroum Bernardianto . 2020. Participatory supervision of communities in concurrent elections of the President/Vice president and Legislative elections of the year 2019 in Kapuas Regency

politik berlangsung simpatik dan meminimalisir aspek violatif dari pesta demokrasi.

Dengan adanya pengawasan terhadap penyelenggaraan Pemilu dari dalam dan luar lembaga penyelenggara, diharapkan pemilu dapat terlaksana dengan demokratis dan memenuhi azas Pemilu. Pada tahapan pelaksanaan Pemilu, Bawaslu pusat maupun di daerah, berhak melakukan pengawasan terhadap peserta Pemilu dan juga terhadap penyelenggara Pemilu. Apabila dalam tahapan Pemilu ditemukan adanya pelanggaran maka Bawaslu akan melakukan tindakan dengan kewenangannya.

\section{KESIMPULAN}

Praktek pengawasan partisipasitif masyarakat dalam pemilu serentak Presiden/Wakil Presiden dan Pemilu Legislatif 2019 di Kabupaten Kapuas dilaksanakan oleh masyarakat dengan membentuk “Kampung Pengawasan Partisipasif” yang dilaksanakan di Kecamatan Basarang yakni Desa Basarang Jaya, Kecamatan Selat yakni Kelurahan Selat Dalam dan Kecamatan Kapuas Hulu di Desa Dirung Koram.

Kampung Pengawasan Partisipatif adalah gagasan yang muncul dari inisiatif masyarakat sendiri untuk mendapatkan pemahaman tentang Pemilu dan pastinya dapat meminimalisir terjadinya pelanggaran pada saat berlangsungnya tahapan Pemilu. Kampung Pengawasan Partisipatif juga menjadi bukti telah terbentuknya partisipasi masyarakat untuk bersamasama menjaga Pemilu yang aman dan damai.

Kampung Pengawasan Partisipatif Desa Dirung Koram dilaksanakan dalam bentuk kegegiatan Kampung Pengawasan Partisipatif Pemilu Masyarakat telah memberikan kontribusi cukup signifikan terhadap hasil pelaksanaan pemilu di wilayah tersebut, hampir semua desa/kelurahan yang menjadi Kampung Pengawasan Partisipatif Pemilu berhasil melaksanakan kegiatan pemilu dengan aman, tertib, lancar tanpa ada kecurangan yang diukur dengan $0 \%$ laporan pelanggaran. Dengan capaian tersebut, Bawaslu
Kabupaten Kapuas memberikan apresiasi kepada kawasan, dimana masyarakatnya punya inisiatif untuk berperan aktif melakukan pengawasan partisipatif pemilu. Bentuk apresiasi dalam pemberian piagam penghargaan kepada desa/kelurahan yang telah bekerjasama menjaga Pemilu yang aman dan damai.

Adapun saran yang peneliti berikan adalah perlu peningkatan kegiatan pelatihan pengawas pemilu partisipatif pada kelompok - kelompok masyarakat di tingkat desa/kelurahan disemua wilayah kecamatan agar bisa berperan lebih aktif dalam memberikan wawasan pengetahuan kepemiluan dan pengawasan kepada lapisan masyarakat. Dan Memberikan lebih banyak sosialisasi kepada lapisan masyarakat, terutama kepada para remaja yang baru mengenal tentang dunia politik. Mengingat usia mereka yang sangat labil dan rentan terbujuk hal-hal negatif dalam kampanye Pemilu karena kurangnya wawasan tentang Pemilu dan Pengawasan Pemilu.

\section{REFERENSI}

Budiarjo.Meriam 2002. Dasar-Dasar Ilmu Politik. PT. Grafindo Jaya Utama Jakarta.

Badan Pengawas Pemilu RI, 2017. Panduan Pusat Pengawasan Partisipatif.

Cornelis Rintuh dan Miar, 2005. Kelembagaan dan Ekonomi Rakyat. Yogyakarta: BPFE Yogyakarta.

Haridison, A. 2016. Strategi Pengawasan Pemilu. Aswaja : Yogyakarta.

Hakim,M.Aziz. 2012. Politik Hukum Sistem Pemilihan Umum di Indonesia pada Era Reformasi. Jakarta : Tesis Universitas Indonesia.

Holil, Soelaiman. 1980. Partisipasi Sosial dalam Usaha Kesejahteraan Sosial. Bandung : Badan penelitian dan pengembangan sosial.

Labolo,M dan Ilham,T. 20I5. Partai Politik dan Sistem Pemilihan Umum di Indonesia, Teori, Konsep dan Isu Strategis. Jakarta : Raja Grafindo Persada

Murafer, Yakobus Rochard. 2018. Peningkatan Pengawasan Partisipatif oleh Panwaslu Kota Jaya 
Pura Dalam Pemilihan Gubernur dan Wakil

Gubernur Provinsi Papua Tahun 2018 di Kota

Jayapura.Jurnal Politik \& Pemerintahan Vol.2

No.2 Desember 2018.

Ratnia Solihah, Arry Bainus dan Iding Rosyidin. 2018.

Pentingnya Pengawasan Partisipatif Dalam

Mengawal Pemilihan Umum Yang Demokratis. Jurnal Wacana Politik Vol.3 No.I Maret 2018.

Pito,T.A dkk. 2006. Mengenal Teori-Teori Politik Dari Sistem Politik Sampai Korupsi. Nuansa : Bandung. Surbakti,R dan Fitrianto,H. 20I5. Transformasi Bawaslu dan Partisipasi Masyarakat Dalam Pengawasan Pemilu, Kemitraan Partnership. Jakarta :.Buku online.

Suswantoro, G, 20I5. Pengawas Pemilu Partisipatif. Gerakan Masyarakat Sipil Untuk Demokrasi. Jakarta : Erlangga.

Siti Malikhatun Badriyah, 20I0. Penemuan Hukum Dalam Konteks Pencarian Keadilan.(Semarang: Badan Penerbit Universitas Dipenogoro.

Soerjono Soekanto, 1993. Faktor-Faktor Yang Mempengaruhi Penegakan Hukum. Jakarta: PT. Rajawali Pers 